PREPARED FOR THE U.S. DEPARTMENT OF ENERGY, UNDER CONTRACT DE-AC02-76CH03073

PPPL-3965

PPPL-3965

UC-70

Deposition Diagnostics for Next-step Devices

by

C.H. Skinner, A.L. Roquemore, the NSTX Team,

A. Bader and W.R. Wampler

June 2004

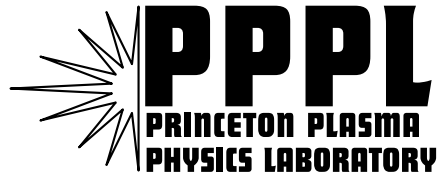

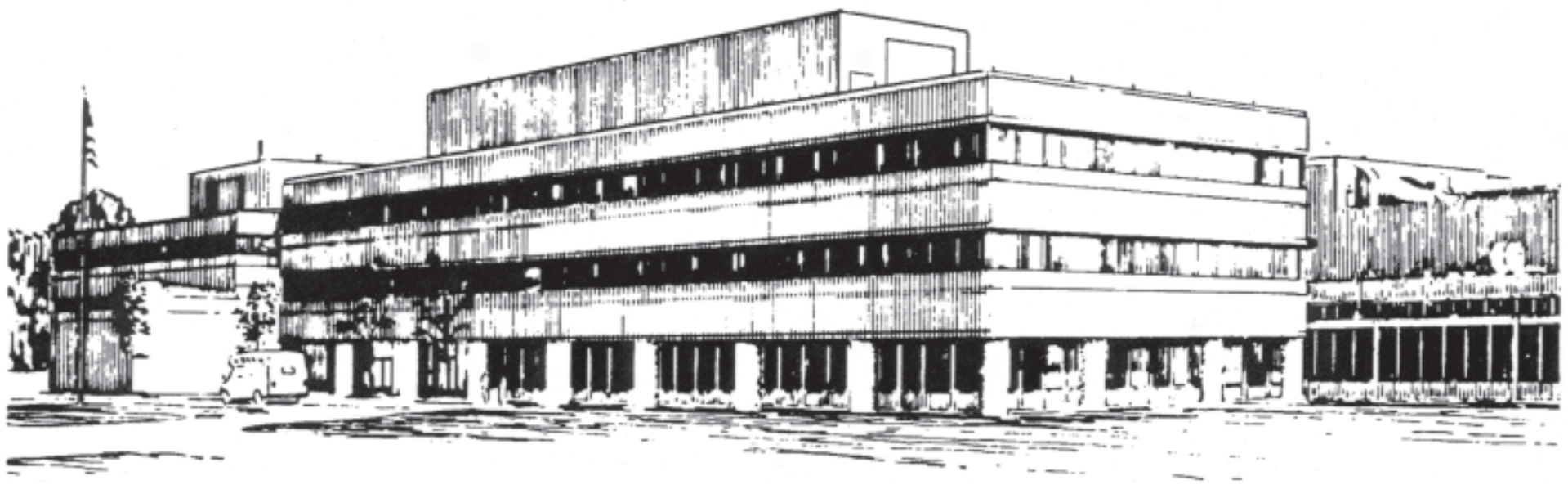

PRINCETON PLASMA PHYSICS LABORATORY PRINCETON UNIVERSITY, PRINCETON, NEW JERSEY 


\section{PPPL Reports Disclaimer}

This report was prepared as an account of work sponsored by an agency of the United States Government. Neither the United States Government nor any agency thereof, nor any of their employees, makes any warranty, express or implied, or assumes any legal liability or responsibility for the accuracy, completeness, or usefulness of any information, apparatus, product, or process disclosed, or represents that its use would not infringe privately owned rights. Reference herein to any specific commercial product, process, or service by trade name, trademark, manufacturer, or otherwise, does not necessarily constitute or imply its endorsement, recommendation, or favoring by the United States Government or any agency thereof. The views and opinions of authors expressed herein do not necessarily state or reflect those of the United States Government or any agency thereof.

\section{Availability}

This report is posted on the U.S. Department of Energy's Princeton Plasma Physics Laboratory Publications and Reports web site in Fiscal Year 2004. The home page for PPPL Reports and Publications is: http://www.pppl.gov/pub_report/

DOE and DOE Contractors can obtain copies of this report from:

U.S. Department of Energy

Office of Scientific and Technical Information

DOE Technical Information Services (DTIS)

P.O. Box 62

Oak Ridge, TN 37831

Telephone: (865) 576-8401

Fax: (865) 576-5728

Email: reports@adonis.osti.gov

This report is available to the general public from:

National Technical Information Service

U.S. Department of Commerce

5285 Port Royal Road

Springfield, VA 22161

Telephone: $1-800-553-6847$ or

(703) $605-6000$

Fax: (703) 321-8547

Internet: http://www.ntis.gov/ordering.htm 


\title{
Deposition diagnostics for next-step devices
}

C. H. Skinner, A. L. Roquemore, and the NSTX team,

Princeton Plasma Physics Laboratory, Princeton, N. J., 08543

A. Bader,

The Cooper Union for the Advancement of Science and Art, New York, NY, 10003

W. R. Wampler,

Sandia National Laboratory, Albuquerque, N.M. 87175

\begin{abstract}
:
The scale-up of deposition in next-step devices such as ITER will pose new diagnostic challenges. Codeposition of hydrogen with carbon needs to be characterized and understood in the initial hydrogen phase in order to mitigate tritium retention and qualify carbon plasma facing components for DT operations. Plasma facing diagnostic mirrors will experience deposition that is expected to rapidly degrade their reflectivity, posing a new challenge to diagnostic design. Some eroded particles will collect as dust on interior surfaces and the quantity of dust will be strictly regulated for safety reasons - however diagnostics of in-vessel dust are lacking. We report results from two diagnostics that relate to these issues. Measurements of deposition on NSTX with $4 \mathrm{~Hz}$ time resolution have been made using a quartz microbalance in a configuration that mimics that of a typical diagnostic mirror. Often deposition was observed immediately following the discharge suggesting that diagnostic shutters should be closed as soon as possible after the time period of interest. Material loss was observed following a few discharges. A novel diagnostic to detect surface particles on remote surfaces was commissioned on NSTX.
\end{abstract}




\section{INTRODUCTION}

The edge plasma and first wall in tokamaks are a strongly coupled system whose interactions span an extraordinary range, from $\mathrm{eV}$ scale atomic interactions to hundred megajoule disruptions - a span of 27 orders of magnitude. Confidence in projecting the performance of burning plasmas is based on decades of work, mostly in machines with carbon plasma facing components[1,2]. This, together with the robustness of carbon under transient heat loads, has led to the choice of carbon as the candidate material for the ITER divertor target plate. While manageable on contemporary machines, the impact of erosion/deposition on plasma facing materials will drastically scale up with the increase in stored energy and pulse length in next-step devices (Table 1). Diagnostic development to characterize erosion and deposition on plasma facing components (PFC) in current tokamaks is a key step to challenge and validate models of these processes and will be essential for the successful operation of next-step devices.

Eroded carbon together with hydrogen isotopes from the plasma can redeposit as an amorphous hydrocarbon layer. In current tokamaks, hydrogen rich layers affect fueling efficiency and plasma density control and are not well thermally connected to the substrate, leading to much higher surface temperatures[3]. On ITER, codeposition of carbon with tritium can rapidly lead to excessive accumulation of tritium. The amount and location of hydrocarbon deposits in the hydrogen / deuterium phases of ITER will be a key factor in the decision of whether it will be possible to use carbon at all in the tritium phase. The impact of present limitations in wall diagnostics on development and testing of predictive modeling codes for next-step devices is highlighted in ref. [4].

The erosion of deposited layers by transient events such as edge localized modes (ELMs) and disruptions can produce fine debris that can contaminate the plasma core[5] or be redeposited at undesirable locations. In next-step devices the amount of dust generated is likely to scale up by two or three orders of magnitude as the erosion increases both with the pulse length and the increase in heat flux during ELMs and disruptions. Dust will be radiologically and chemically hazardous. Tritiated dust becomes statically charged through 
the emission of beta electrons and this enhances its mobility [6]. Dust will go from being largely inconsequential, to a major factor in safety assessments, site licensing and tokamak operations. To protect the public the inventory of dust in ITER will be strictly regulated. Proposed limits are 10-20 kg of beryllium dust on hot surfaces, $100 \mathrm{~kg}$ for carbon dust, and $100-400 \mathrm{~kg}$ for tungsten dust (depending on the containment function of the ITER building)[7]. Before tokamak operations can begin, regulatory bodies will need to be convinced that such limits are satisfied, however diagnostics to estimate the dust inventory are in their infancy.

Deposition on windows and mirrors can 'blind' optical diagnostics. Experimentally, a $21 \mathrm{~nm}$ coating of carbon reduced the reflectivity of a stainless steel mirror from $70 \%$ to $18 \%$ at a wavelength of $470 \mathrm{~nm}$ [8]. In ITER, mirrors for the divertor impurity monitor are planned in a location in the divertor dome, less than $1 \mathrm{~m}$ away from the divertor target plate which will experience $\mathrm{cm}$-scale erosion. Mirror cleaning techniques such as laser ablation[9], will be essential to maintain mirror reflectivity in next-step devices.

Quartz crystal microbalances have been widely used to monitor the growth of thin films in real time during vacuum deposition[10,11]. They have been applied to the TdeV tokamak[12], to ASDEX[13,14], TEXTOR[15] and JET[16,17]. Quartz microbalances are not sensitive to dust presumably because of the lack of mechanical coupling between the particles and quartz crystal[18]. A capacitive diaphragm microbalance has been proposed for deposition measurements in the neutron environment of a DT burning next-step device[19]. Glowing particles are often observed in plasmas[20] and can be detected by laser scattering[21]. Surface dust has been identified by IR emission[22] or laser ablation[23]. Laboratory tests of a novel electrostatic dust detector were presented in ref. [18] and recent results from NSTX are reported in section III.

\section{DEPOSITION MEASUREMENTS IN NSTX.}

The National Spherical Torus Experiment (NSTX) research program is aimed at exploring the physics of high beta and high confinement in a low aspect ratio device and to demonstrate non-inductive current generation and sustainment[24]. The device parameters 
are: plasma major radius: $0.85 \mathrm{~m}$, minor radius: $0.68 \mathrm{~m}$, toroidal field of up to $0.45 \mathrm{~T}$, plasma current up to $1.5 \mathrm{MA}$ and pulse duration up to $1 \mathrm{~s}$. The plasma can be heated by up to $5 \mathrm{MW}$ neutral beam injection and $6 \mathrm{MW}$ of high harmonic fast wave RF at $30 \mathrm{MHz}$. Plasma facing components that are in contact with the plasma are protected by a combination of graphite and carbon fiber composite tiles. Ex-vessel ion beam analysis showed that deposited layers are composed of carbon, deuterium and oxygen[25].

Two quartz microbalances[26] were set up to measure the deposition in real time. They were mounted back-to-back on a copper plate and positioned inside a standard $10.16 \mathrm{~cm}$ i.d. vacuum tee that was attached to a gate valve (Fig. 1). The microbalances were UHV compatible and capable of being baked to $450{ }^{\circ} \mathrm{C}$. They each contained a quartz crystal that oscillated at a frequency close to $6 \mathrm{MHz}$; the precise frequency depended on the deposited mass and crystal temperature. One quartz crystal faced the plasma and had a remotely controllable pneumatically operated shutter. A second quartz crystal was mounted behind the first and faced the back of the vacuum tee that was $2.5 \mathrm{~cm}$ away. A silicon witness coupon also faced the plasma and was positioned above the front facing quartz crystal. This provides an additional record of the cumulative deposition. The assembly was connected to the vessel by a tube $38.5 \mathrm{~cm}$ long, $9.7 \mathrm{~cm}$ diameter. The distance from the front crystal to the last closed flux surface was $77 \mathrm{~cm}$. This location far from plasma minimized the heat flux incident on the detector and enabled the thickness of the deposited layer to be monitored before and after a discharge. Leads $51 \mathrm{~cm}$ long connected the $6 \mathrm{MHz}$ signals from a local oscillator through a vacuum feedthrough. Type $\mathrm{K}$ thermocouples were used to monitor the temperature. The oscillation frequency was measured with a $20 \mathrm{MHz}$ reference oscillator via Modelock ${ }^{\mathrm{TM}}$ system that is immune to mode hopping. The manufacturers specify a thickness resolution of $0.01 \mathrm{~nm}$ for unit density, accuracy $0.5 \%$ and $4 \mathrm{~Hz}$ sampling rate. With the gate valve closed, the unit could be withdrawn from the machine to change the quartz crystals and silicon coupons when desired.

The deposition geometry is generically representative of diagnostic mirrors that view the plasma through a tube. For example, the ITER divertor impurity monitor design has a first mirror in the divertor dome $93 \mathrm{~cm}$ from the outer divertor target plate. Some hydrocarbon 
radicals have low sticking coefficients (e.g. $\mathrm{C}_{2} \mathrm{H}_{\mathrm{x}>2}$ [27]) and may be transported down tubes to deposit on surfaces without a direct line of sight to the plasma such as the back facing quartz crystal.

Two deposition monitor controllers provided an analog output that was used for measurements. The density of hydrocarbon films can range from 0.9 to $2.4 \mathrm{~g} / \mathrm{cm}^{3}$ [28] and for estimating the film thickness we assume a density of $1.6 \mathrm{~g} / \mathrm{cm}^{3}$ (measurements of the film density are not available). The thickness and temperature data was digitized at $10 \mathrm{~Hz}$ and the data was recorded from $60 \mathrm{~s}$ before the initiation of each discharge and readout $100 \mathrm{~s}$ before the subsequent discharge with a maximum data record duration of 819 s. To minimize bit noise the data was postprocessed with 5 point smoothing. The accuracy of the digitizer timing to within 1 sample $(0.1 \mathrm{~s})$ was confirmed by separate tests with a timing signal and by the correct timing of the electrical pick up on the thermocouples recorded by the same digitizer.

Deposition data was recorded over 497 discharges between Jan $13^{\text {th }}-$ Feb $14^{\text {th }} 2003$. The deposition accumulated slowly averaging $0.059 \mu \mathrm{g} / \mathrm{cm}^{2}$ or 0.37 n.m per discharge. A sequence of 5 discharges with unusually high deposition occurred during coaxial helicity injection (CHI) experiments[29] initiated with 96 torr-l of deuterium gas injection. Deposition continued for 12 seconds after the discharge (Fig. 2).

Initially the crystals were water cooled to $20 \mathrm{C}$. However long water lines between the cooler and crystals resulted in a temperature oscillation of 1 degree with a period of about 15 minutes and, since the oscillation frequency of a quartz crystal is also temperature dependent, a corresponding frequency change. For discharges after 110048 the water cooler was off and the temperature remained constant to better than 0.2 degrees (the bit size of the digitizer) for more than 10 minutes. A $0.2{ }^{\circ} \mathrm{C}$ change in the crystal temperature will produce the same frequency change as 0.075 n.m of deposition. Fig. 3 (a) shows weak deposition after a 500kA RF heated discharge. The crystal temperature during this discharge is plotted in Fig. 3 (b) and an equivalent n.m. scale is shown on the right hand $\mathrm{Y}$-axis. The large transient at $\mathrm{t}=0$ is due to electrical pickup. It can be seen that there is no detectible temperature change and the frequency change in this time period appears to be occurring solely to deposition. 
Surprisingly a total of $15.9 \mu \mathrm{g} / \mathrm{cm}^{2}$ of material loss was observed after 7 discharges (Fig.4). While these discharges experienced disruptions, other disruptive discharges did not show material loss. The cause of the material loss remains unclear.

After the 2003 experimental campaign, the crystals were retrieved from NSTX and examined by ion beam analysis at Sandia National Laboratory. The carbon areal density was measured by proton scattering at $1.735 \mathrm{MeV}$ where there is a resonance in the elastic scattering cross section that enhances the signal/background. Deuterium was analyzed by counting protons from the $\mathrm{d}\left({ }^{3} \mathrm{He}, \mathrm{p}\right){ }^{4} \mathrm{He}$ nuclear reaction with an incident ${ }^{3} \mathrm{He}$ energy of 0.7 $\mathrm{MeV}$. The absolute accuracy of the measurements is about $\pm 10 \%$. The deuterium and carbon areal density on the front facing quartz crystal was $0.2 \mu \mathrm{g} / \mathrm{cm}^{2}$ and $11.4 \mu \mathrm{g} / \mathrm{cm}^{2}$. The surface atomic concentration of oxygen relative to carbon was measured by $\mathrm{x}$-ray photoelectron spectroscopy, and assuming this is representative of the whole film, we calculate an areal density of oxygen of $1.9 \mu \mathrm{g} / \mathrm{cm}^{2}$. The total areal density of deuterium, carbon and oxygen is then $13.5 \mu \mathrm{g} / \mathrm{cm}^{2}$ in excellent agreement with the total areal density of $13.3 \mu \mathrm{g} / \mathrm{cm}^{2}$ measured by the quartz microbalance. An electronics problem prevented time resolved measurements from the back facing crystal during this period, however the deposited mass was measured by ion beam analysis to be $1.3 \mu \mathrm{g} / \mathrm{cm}^{2}$, about $10 \%$ of the deposition on the front facing crystal.

The deposition was generally weak and often obscured by bit noise. Of the total cumulative deposition (not including the material loss) of $29.2 \mu \mathrm{g} / \mathrm{cm}^{2}$, only $5.3 \mu \mathrm{g} / \mathrm{cm}^{2}$ could be clearly identified as an increment within 2 seconds of a discharge. However small bit-level deposition continued to accumulate as evidenced by the absolute measurement of the crystal frequency. It appears that material migration, possibly evaporation of polymer-like films, is occurring after a discharge. Mirror reflectivity is affected by only $10 \mathrm{~nm}$ of deposition[8] and for an unshuttered mirror, this would occur in 27 discharges in the present geometry. These results highlight the need for diagnostic shutters that are only open when measurements are needed in order to minimize deposition on diagnostic windows and mirrors. 


\section{NOVEL ELECTROSTATIC SURFACE PARTICLE DETECTION DEVICE.}

A novel device to detect particles that have settled on a surface has recently been developed[18]. This device is robust and easy to implement in difficult-to-access locations. It consists of two closely interlocking grids of wires on a circuit board (Fig. 5). To date the spacings have ranged from $125 \mu \mathrm{m}$, the smallest that could be conveniently obtained from standard circuit board technology, to $762 \mu \mathrm{m}$. The two grids are electrically isolated and can stand off a DC voltage of $800 \mathrm{~V}$ or more. Experimental tests [18] at bias voltages of $30-50 \mathrm{~V}$ showed that the device was capable of detecting particles settling on surfaces in air and in vacuum. When a conductive particle settles on the grid, a miniature spark was generated. The resulting current typically vaporizes the particle and removes the short circuit, resetting the detector. The current passes through a $51 \Omega$ resistor generating a transient irregular voltage signal. The signal is then conditioned by a $1.3-31 \mathrm{kHz}$ band pass $\mathrm{RC}$ filter and input to standard nuclear counting electronics providing a record of the event (Fig. 6). The operating principle is electrostatic not gravimetric and hence the device does not provide an absolute measure of the areal density of particles - such a diagnostic still needs to be developed for tokamaks. However a significant correlation was found between the mass of impinging particles and the number of counts registered by the electronics, especially at fine grid spacing (Fig. 7).

Dust particles that had accumulated on a viewport the bottom of the NSTX vessel at bay B during the period Jan 20 $0^{\text {th }}-$ March $5^{\text {th }} 2004$ (520 discharges) were examined with a digital optical microscope (Fig. 8). The viewport views the plasma through a $5 \mathrm{~cm}$ wide slot on the inner lower passive plate and is $40 \mathrm{~cm}$ below the ATJ graphite tiles. The particle density was measured with NIH Image software to be 313,500 particles $/ \mathrm{cm}^{2}$ with the most common size being at the pixel dimension of $1 \mu \mathrm{m}$. The count median diameter was calculated from the size distribution to be $2.06 \mu \mathrm{m}$, the geometric standard deviation $2.08 \mu \mathrm{m}$ and diameter of average mass $4.61 \mu \mathrm{m}$. These values are similar to those found in other tokamaks[30]. The specific surface area of tokamak dust is about $3 \mathrm{~m}^{2} / \mathrm{g}[30]$ so at this viewport the effective surface area increased by $80 \%$ due to the dust. This direct viewing method gives a direct measure of the particle areal density and has the advantage that the dust 
is not disturbed by a dust collection technique. Previously, dust samples were taken from the interior of NSTX with a vacuum pump and filter attachment and the results will be reported in ref. [31].

The electrostatic dust detector was reconfigured for NSTX to provide time resolved measurements and to track the events that produced the dust. Two grids of spacing $125 \mu \mathrm{m}$ and $254 \mu \mathrm{m}$ were mounted on a $15.24 \mathrm{~cm}$ conflat flange (Fig. 9). A glass slide was placed between the grids in a pre-weighed tray to collect dust for calibration purposes. The materials used were chosen to be compatible with a high vacuum environment. The copper wires were soldered to the circuit board with $96 \%$ tin/ $4 \%$ silver solder. Alumina standoffs supported the circuit board. The screws were ventilated and isolated from the circuit board by a thin sheet of mica. Stainless steel wire and sheet were used to limit the motion of screws should they loosen under vibration. The assembly was mounted under a gate valve at the bottom of NSTX, directly under a $5 \mathrm{~cm}$ wide slot in the lower divertor at bay $\mathrm{C}, 30^{\circ}$ toroidally from the viewport at bay B. The assembly was wrapped in heater tape and baked to a temperature of 65 ${ }^{\circ} \mathrm{C}$ for 36 hours to outgas any volatile molecules from the components before the gate valve was opened to the NSTX vacuum. The detection electronics was the same as used in the laboratory experiments[18] except that the $50 \mathrm{~V}$ bias voltage was supplied via a $17 \mathrm{~m}$ long cable. The current was limited to $200 \mathrm{~mA}$. Helium glow discharge cleaning is performed between plasma discharges on NSTX with the vessel at a pressure of 4 mtorr. To prevent any parasitic discharges on the grid the bias voltage was automatically disconnected during the period of the glow. The output of the single channel analyzer was fed to a Bi Ra 911 latching scalar with a $256 \mathrm{k}$ memory module and data acquired at $1 \mathrm{kHz}$ from a period of $-10 \mathrm{~s}$ to + $55 \mathrm{~s}$ with respect to the initiation of the plasma.

First results were obtained 9 April 2004. Typically events are observed on both grids in the current ramp down phase of the discharge. Reconnection events occur during the ramp down and are evident in transients in the plasma current and in the CII emission from the lower divertor. Fig. 10 shows a series of events on the channel 2 grid following transients in CII and D-alpha emission due to ELMs. In a check for other potential causes of events, intense illumination from a photographic flash unit did not cause any response from the 
detector. No signal is observed if the gate valve is closed. We also plan to install a copper mesh to shield the detector from any plasma that may be transported across field lines to ensure this is not causing a response.

Recently, the dust collected on the glass slide between the grids was retrieved and the dust analysed by Raman scattering with a helium neon laser[32]. Particles ranging in size from 2 to 30 microns were found to be disordered graphitic (sp2) carbon, easily recognized by the presence of the typical D-band $\left(\sim 1330 \mathrm{~cm}^{-1}\right)$ and G-band $\left(1585 \mathrm{~cm}^{-1}\right)$. Also found on the slide was a linear fiber 30 micron diameter with a $-\mathrm{C} \equiv \mathrm{N}-$ stretching band at $2244 \mathrm{~cm}^{-1}$, probably a nitrile rubber, and an irregular fiber with an amide band at $1669 \mathrm{~cm}^{-1}$.

For next-step devices, an array of dust detectors could be inexpensively installed over wide areas so that, in conjunction with quantitative dust mass diagnostics (still to be developed), they could improve confidence that dust inventory limits were not exceeded. This device could be applied to any situation where information on the presence of electrically conductive dust on hard-to-access areas is important. Further optimization of the detector is possible, in particular, nanotechnology may be applied to reduce the grid spacing to detect single micron-scale particles, and neutron damage resistant materials would be used in DT tokamaks. It may even be possible to use large grids in dusty areas to actively control the dust inventory by instantly vaporizing any particles that settle on the grid.

\section{DISCUSSION.}

ITER will initially be a plasma wall interaction experiment of unprecedented scale and complexity. Managing the large scale-up in stored energy and pulse duration requires diagnostics to measure wall and plasma edge phenomena and technology to mitigate their effects. The complex and varied discharge history of current tokamaks makes post-campaign 'archeological' studies of wall samples in current tokamaks of limited utility - real time measurements are necessary to challenge erosion/deposition models and gain a predictive understanding of processes occurring at the plasma boundary and wall. Only if plasma wall interactions issues are successfully addressed will ITER be able to study burning plasmas. While activities continue to take place on these issues, diagnostics of the first wall and 
dedicated run time in present tokamaks aimed at gaining a predictive understanding of the interactions between a burning plasma and material surfaces are not seen as a high priority. However the critical choice of first wall materials requires deposition diagnostics in ITER's

hydrogen/deuterium phase. Safe operations require knowledge of in-vessel dust levels. Optical diagnostics require technology to mitigate first mirror deposition. There is an urgent need to develop novel diagnostics and dedicate more run time in present tokamaks to this challenging area. For a next-step tokamak to be able to study burning plasmas, there is no other choice.

\section{ACKNOWLEDGEMENTS}

The authors thank A. Costley and G. Federici for stimulating discussions and B. Davis, G. Gibilisco, T. Holoman, D. LaBrie, L. Ciebiera and M. Dimattia, T. Holloman, T. Provost, P. Roney, H. Schneider and J. Wertenbaker for technical assistance. We thank D. Cole, J. Gold and V. Pajcini of Evans East for the XPS surface analysis. A. Bader acknowledges support from the 2003 National Undergraduate Fellowships in Plasma Physics and Fusion Energy Sciences. This work was funded by U.S. DOE Contract Nos. DE-AC02-76CH0307. 


\section{REFERENCES}

[1] G. Federici, C. H. Skinner, J. N. Brooks, J. P. Coad, C. Grisolia, A. A. Haasz, A. Hassanein, V. Philipps, C. S. Pitcher, J. Roth, W. R. Wampler, D. G. Whyte, Nucl. Fus., 41, 1967 (2001).

[2] G. Federici et al., J. Nucl. Mater., 313-316, 11 (2003).

[3] C. H. Skinner, N. Bekris, J. P. Coad, C. A. Gentile, A. Hassanein, R. Resiwig and S.Willms, Phys. Scripta T 103, 34 (2003)

[4] G. F. Counsell, J. P. Coad, G. Federici, K. Krieger, V. Philipps, C. H. Skinner, D. G. Whyte, J. Nucl. Mater., 290-293, 255 (2001).

[5] S. I. Krasheninnikov, Y. Tomita, R. D. Smirnov and R. K. Janev, submitted to Physics of Plasmas.

[6] C. H. Skinner, C. A. Gentile, L. Ciebiera, S. Langish, Fus. Sci. \& Technol. 45, 11 (2004).

[7] S. J. Piet, A. Costley, G. Federici, F. Heckendorn, R. Little, Proceedings of the 17th IEEE/NPSS Symposium on Fusion Engineering, San Diego, October 6-10, 1997, p321, IEEE, Piscataway, NJ, USA (1998).

[8] V. Voitsenya et al., Rev. Sci. Instrum., 72, 475 (2001)

[9] B. W. Brown, C. W. Gowers, P. Nielsen and B Schunke, Rev. Sci. Instrum 66, 3077 (1995).

[10] C. S. Lu and O. Lewis, J. Appl. Phys. 43, 4385 (1972).

[11] J. Janata, Principles of Chemical Sensors (Plenum Press, New York, 1990) p.55.

[12] D. Bourgoin, G. G. Ross. S. Savoie, Y. Drolet, E. Haddad., J. Nucl. Mater., 241-243, 765 (1997).

[13] V. Rhode, H. Maier, K. Krieger, R. Neu, J. Perchermaier, J. Nucl. Mater., 290-293, 317 (2001).

[14] V. Rohde, M. Mayer et al., Physica Scripta, T 102, 25 (2003). 
[15] J. von Seggern, P. Weinhold, T. Hirai, B. Philipps, H. G. Esser, J. Nucl. Mater. 313316, 439-443 (2003).

[16] H. G. Esser, G. Neil, P. Coad, G. F. Matthews, D. Jolovic, D. Wilson, M. Freisinger and V. Philipps, Fusion Eng. Des., 66-68, 855 (2003).

[17] H. G. Esser, V Philipps, M. Freisinger, P Coad, G. F. Matthews, G Neil, Proceedings of the $10^{\text {th }}$ International Carbon Workshop for Fusion Application, Juelich, September $17-19^{\text {th }}, 2003$ to be published in Physica Scripta.

[18] A. Bader, C.H. Skinner, A.L. Roquemore, and S. Langish, Rev. Sci. Instrum. 75, 370 (2004).

[19] G. F. Counsell and C. H. Wu, Physica Scripta T91, 70 (2001).

[20] M. Rubel., M. Cecconello, J. A. Malmberg, G. Sergienko, W. Biel, J. R. Drake, A. Hedqvist, A. Huber, V. Philipps, Nucl. Fus., 41, 1087 (2001).

[21] K Narihara et al., Nucl. Fus. 37, 1177 (1997).

[22] R. Reichle, V Basuik, V, Bergeaud, A. Cambe, M. Chantant, E. Delchambre, M. Druetta, E. Gauthier, W. Hess and C. Pocheau, J. Nucl. Mater., 290-293, 701 (2001).

[23] G. T. Razdobarin, G. Federici, V. M. Kozhevin, E. E. Mukhin, V. V. Semenov, S. Y. Tolstyakov, Fus. Sci. \& Technol., 41, 32-43 (2002)

[24] E.J. Synakowski, et al., Nucl. Fus. 43, 1653-1664 (2003).

[25] H. W. Kugel et al., J. Nucl. Mater 290 - 293, 1185 (2001).

[26] Leybold Infinicon, Two Technology Place, East Syracuse,NY; model XTM2P/11231000.

[27] A. von Keudell, C. Hopf, T. Schwarz-Selinger, W. Jacob., Nucl. Fus. 39 (1999) 1451.

[28] T. Schwarz-Selinger et al., J. Appl. Phys., 863988 (1999).

[29] R. Raman et al., Nucl. Fus., 41, 1081 (2001).

[30] W.J. Carmack, R. A. Anderl, R. J. Paweko, G. R. Smolik, K. A. McCarthy, Fus, Eng. Des 51-52, 477 (2000).

[31] J. P. Sharpe, P.W. Humrickhouse, C. H. Skinner, INEEL external report no.: INEEL/EXT-03-01083

[32] Charles Evans Associates. 


\section{LIST OF TABLES:}

Table 1: Scale-up of plasma material interaction issues in ITER. 


\section{LIST OF FIGURES:}

Figure 1. Plasma view of quartz microbalance through a $10 \mathrm{~cm}$ diameter port showing silicon witness coupon, plasma facing quartz crystal and shutter (folded down). The edge of the rear facing quartz crystal can be seen behind the silicon coupon. Thermocouples are mounted besides the quartz crystals.

Figure 2. Deposition on the front facing quartz microbalance during and after $\mathrm{CHI}$ discharge 109588. The discharge was $0.15 \mathrm{~s}$ duration beginning at $\mathrm{t}=0$. The right hand $\mathrm{Y}$-axis is calculated assuming a density of $\rho=1.6 \mathrm{~g} / \mathrm{cm}^{3}$.

Figure 3 (a) Deposition on the front facing quartz microbalance during and after 500kA, RF heated discharge 110154 . The discharge was $0.7 \mathrm{~s}$ duration beginning at $\mathrm{t}=0$. The right hand $\mathrm{Y}$ axis is calculated assuming a density of $\rho=1.6 \mathrm{~g} / \mathrm{cm}^{3}$. Temperature effects are shown to be negligible in plot 3 (b) which has an equivalent $\mathrm{nm}$ scale on the right. The transient at $\mathrm{t}=0$ is due to electrical pickup.

Figure 4. Material loss following discharge 109992.

Figure 5. Photograph of grid of interlocking traces.

Figure 6. (a) Unfiltered signal from dust detector in laboratory tests in air, (b) filtered signal (c) pulses generated when filtered signal has a $0.4 \mathrm{~V}$ magnitude and a negative slope.

Figure 7. Recorded counts vs. the areal density of dust on three grids of spacing $125 \mu \mathrm{m}(\square)$, $381 \mu \mathrm{m}(\mathrm{X})$, and $762 \mu \mathrm{m}(\mathrm{O})$. The line is a second order polynomial fit to the data.

Figure 8. Image of NSTX dust that had settled on the NSTX Bay B lower viewport as recorded by an optical transmission microscope. The image covers 337 x $253 \mu \mathrm{m}$.

Figure 9. Two grids and reference dust collector mounted on a $15 \mathrm{~cm}$ flange for testing in NSTX.

Figure 10. First time resolved events recorded by the NSTX dust detector. Panel (a) shows the response of grid 1 and (b) of grid 2. The lower frame shows large transients in ionized carbon emission at 658 n.m. that occur 10-20 ms before the dust events. 
Table 1: Scale-up of plasma material interaction issues in ITER.

\begin{tabular}{lll}
\hline \hline Parameter & Current Tokamaks & ITER Units \\
\hline $\mathrm{E}_{\text {therm }}\left(\propto \mathrm{R}^{5}\right)$ & $1-15$ & $350 \mathrm{MJ}$ \\
Disruptions & $0.03-1$ & $\approx 10 \mathrm{MJ} / \mathrm{m}^{2}$ \\
Type 1 ELMs & $0.1-0.6 \mathrm{JET}$ & $8-20 \mathrm{MJ}$ \\
Pulse duration & $10-25 \mathrm{JET}$ & $400 \mathrm{~s}$ \\
& 378 Tore Supra & \\
Cumulative run time & $2-8$ & $>200 \mathrm{hours} /$ year \\
Carbon erosion (divertor) & $7-300 \mu \mathrm{m}$ & $>1 \mathrm{~cm} /$ operat. year \\
Carbon deposition & $150 \mu \mathrm{m}$ in $2 \mathrm{~h} 20 \mathrm{~m}$ & $50 \mu \mathrm{m} /$ day \\
(divertor) & $($ Tore Supra) & \\
Tritium injected & $\approx 0.2$ & $120 \mathrm{~g} /$ pulse \\
\hline \hline
\end{tabular}




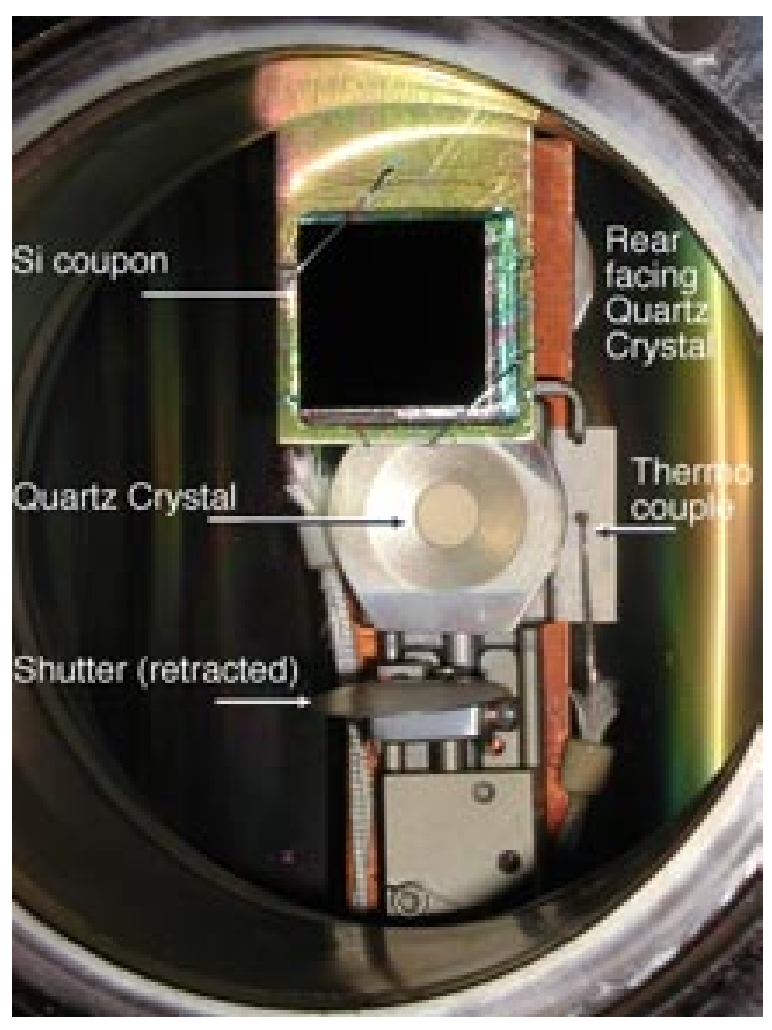

Figure 1. Plasma view of quartz microbalance through a $10 \mathrm{~cm}$ diameter port showing the silicon witness coupon, plasma facing quartz crystal and shutter (folded down). The edge of the rear facing quartz crystal can be seen behind the silicon coupon. Thermocouples are mounted besides the quartz crystals.

Paper G13 C. H. Skinner et al. 


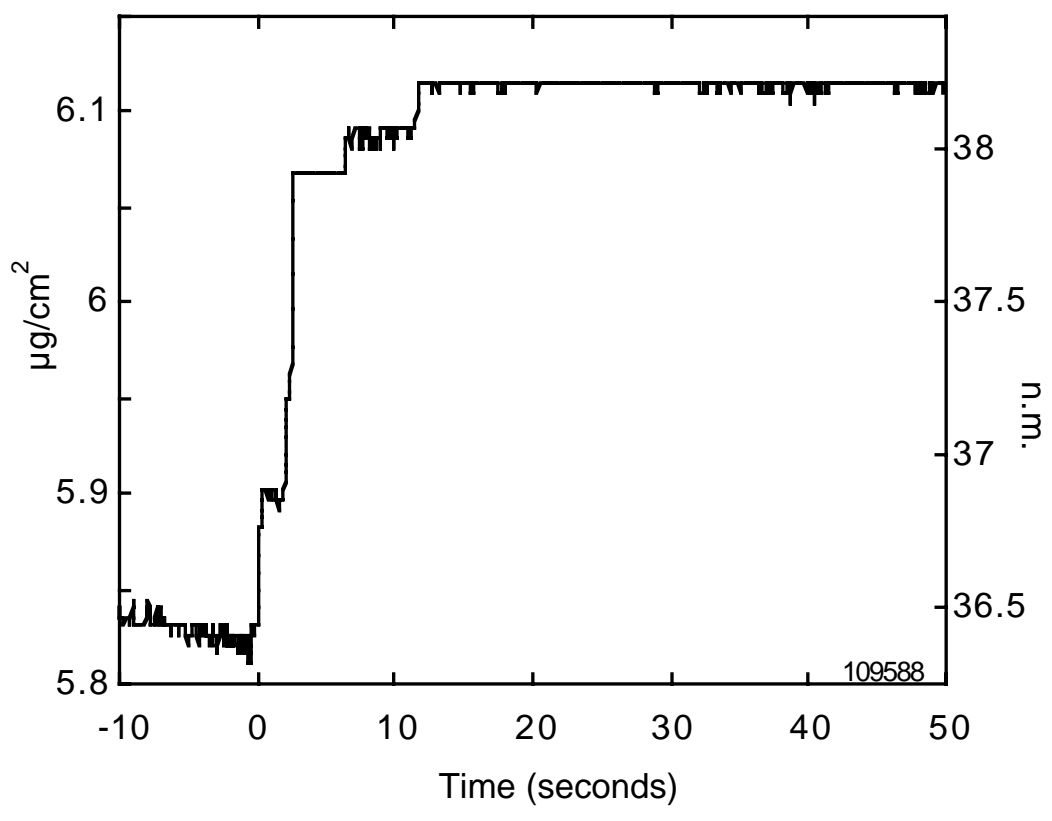

Figure 2. Deposition on the front facing quartz microbalance during and after $\mathrm{CHI}$ discharge 109588. The discharge was $0.15 \mathrm{~s}$ duration beginning at $\mathrm{t}=0$. The right hand $\mathrm{Y}$-axis is calculated assuming a density of $\rho=1.6 \mathrm{~g} / \mathrm{cm}^{3}$.

Paper G13, C. H. Skinner et al. 

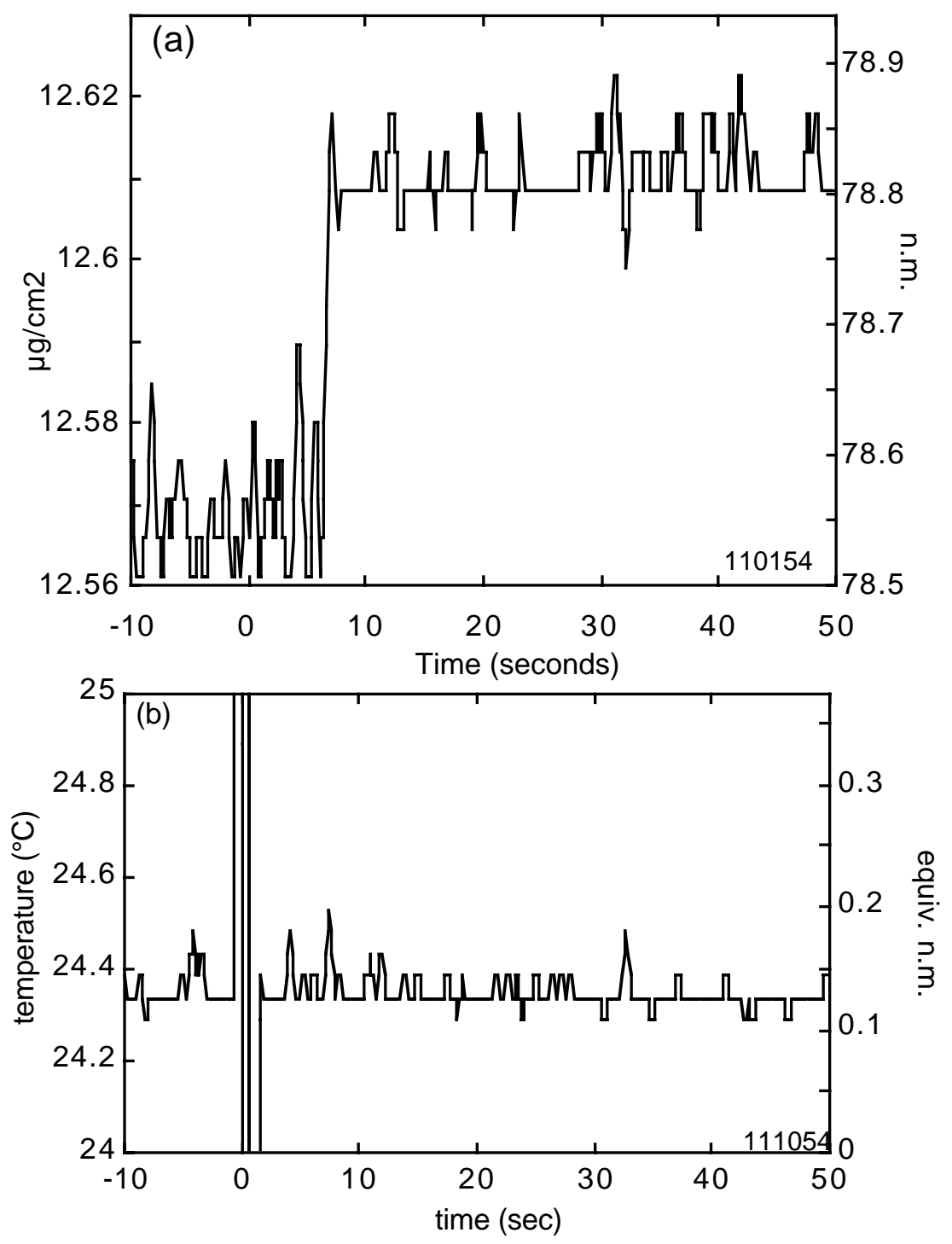

Figure 3 (a). Deposition on the front facing quartz microbalance during and after 500kA, RF heated discharge 110154 . The discharge was $0.7 \mathrm{~s}$ duration beginning at $\mathrm{t}=0$. The right hand $\mathrm{Y}$ axis is calculated assuming a density of $\rho=1.6 \mathrm{~g} / \mathrm{cm}^{3}$. Temperature effects are shown to be negligible in plot 3 (b) which has an equivalent $\mathrm{nm}$ scale on the right. The transient at $\mathrm{t}=0$ is due to electrical pickup.

Paper G13 C. H. Skinner et al. 


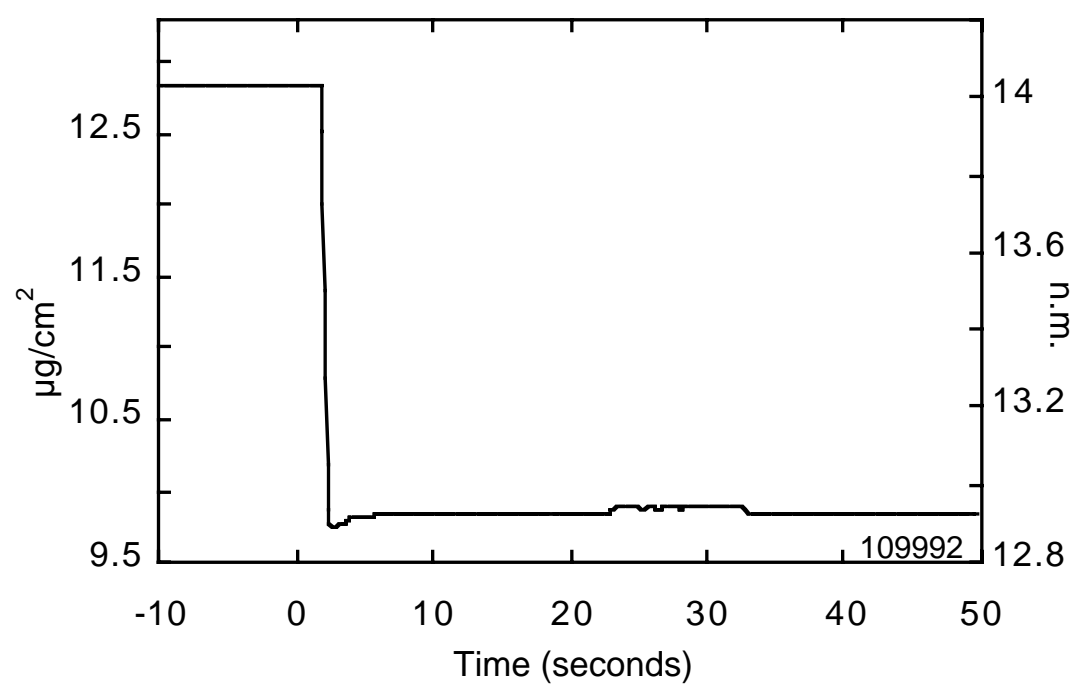

Figure 4. Material loss following discharge 109992.

Paper G13 C. H. Skinner et al. 


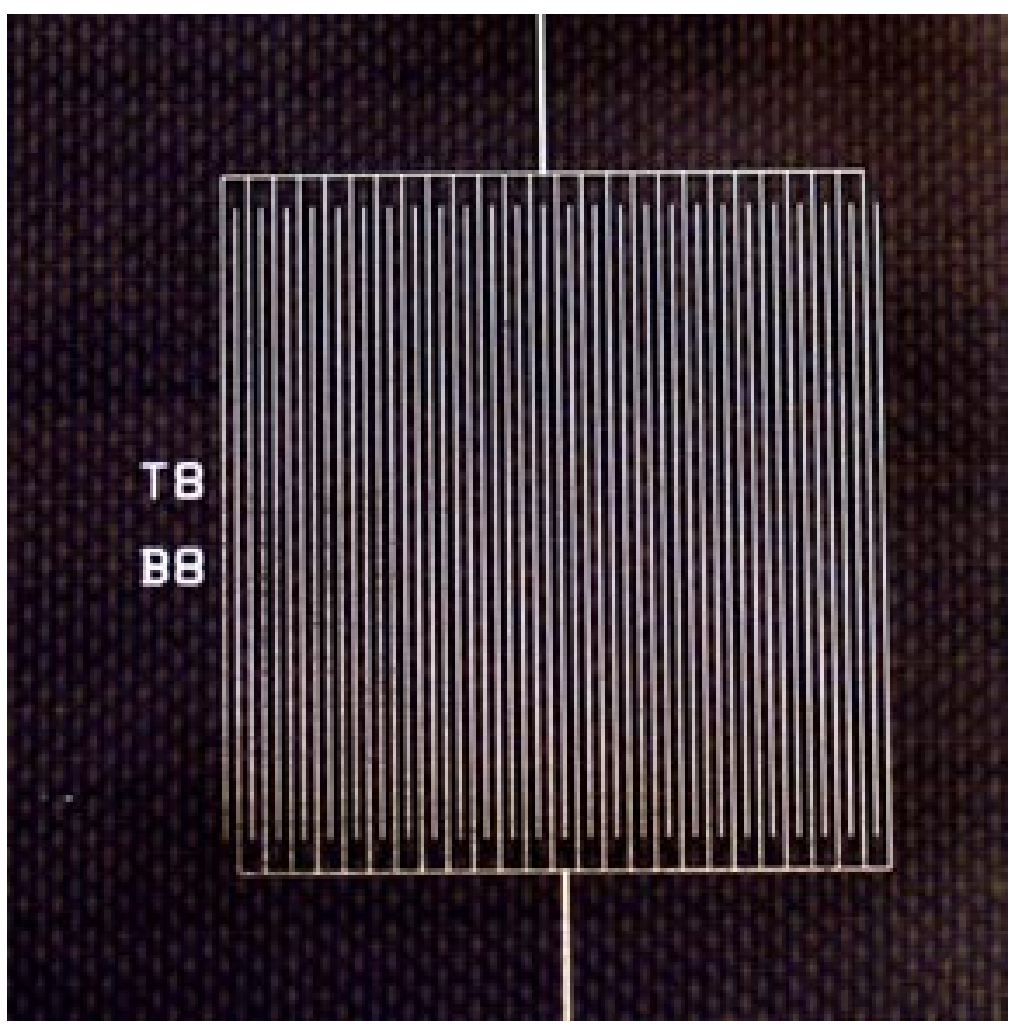

Figure 5. Photograph of grid of interlocking traces.

Paper G13 C. H. Skinner et al. 


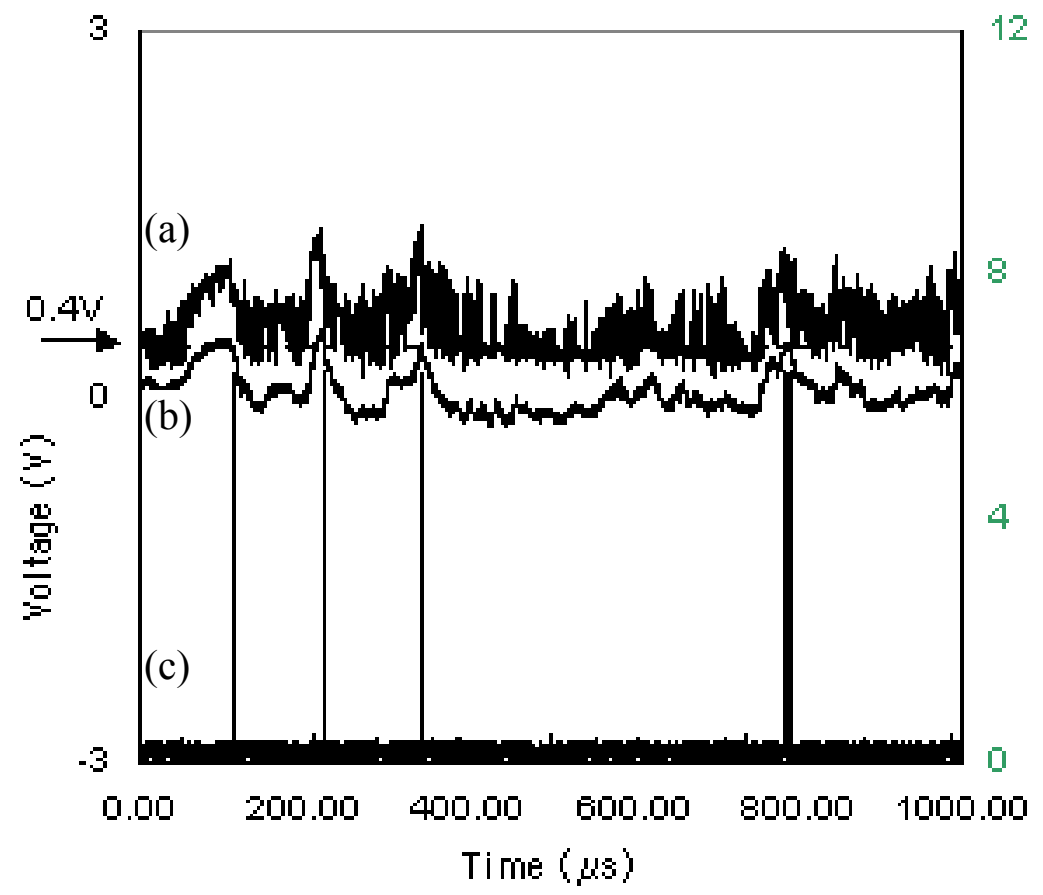

Figure 6. (a) Unfiltered signal from dust detector in laboratory tests in air, (b) filtered signal (c) pulses generated when filtered signal has a $0.4 \mathrm{~V}$ magnitude and a negative slope.

Paper G13 C. H. Skinner et al. 


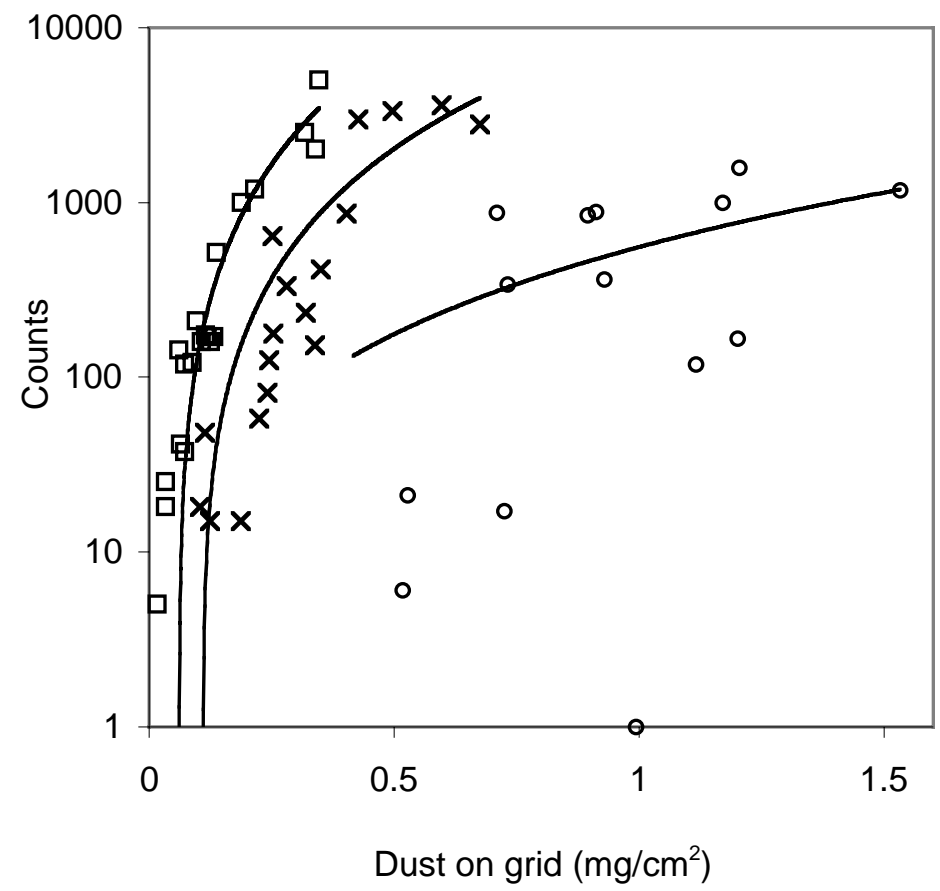

Figure 7. Recorded counts vs. the areal density of dust on three grids of spacing $125 \mu \mathrm{m}(\square)$, $381 \mu \mathrm{m}(\mathrm{X})$, and $762 \mu \mathrm{m}(\mathrm{O})$. The line is a second order polynomial fit to the data.

Paper G13 C. H. Skinner et al. 


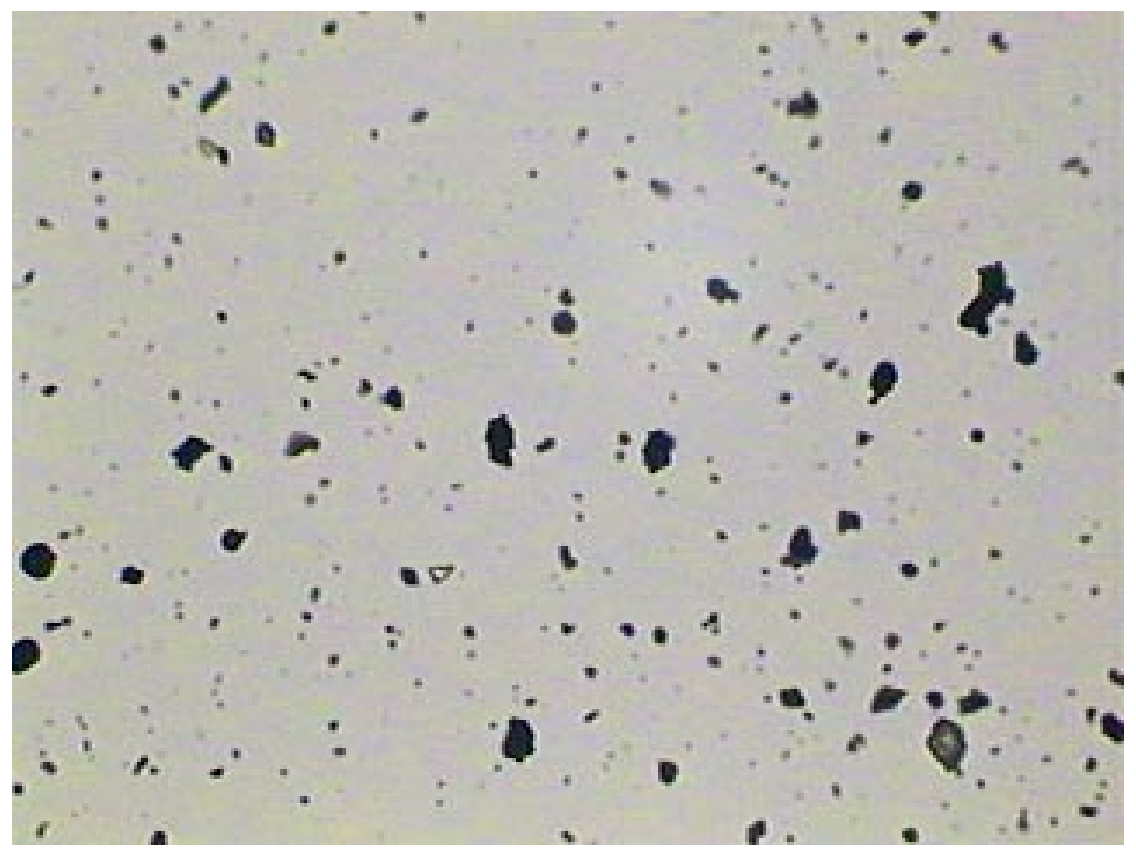

Figure 8. Image of NSTX dust that had settled on the NSTX Bay B lower viewport as recorded by an optical transmission microscope. The images covers 337 x $253 \mu \mathrm{m}$.

Paper G13 C. H. Skinner et al. 


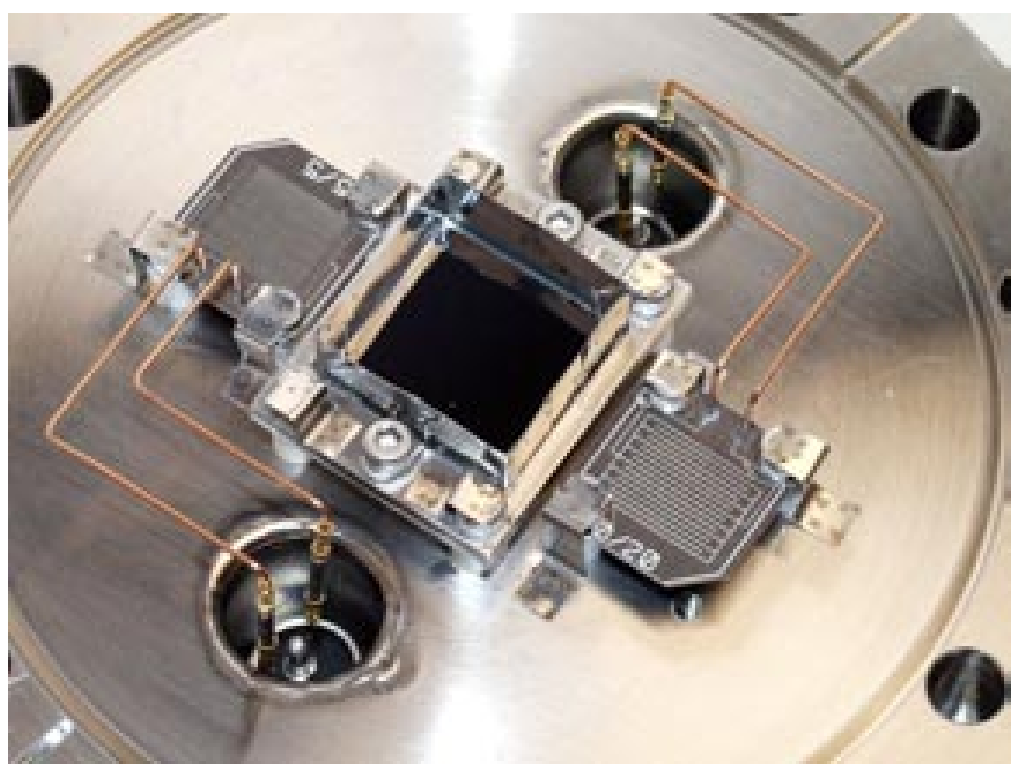

Figure 9. Two grids and reference dust collector mounted on a $15 \mathrm{~cm}$ flange for testing in NSTX.

Paper G13 C. H. Skinner et al. 


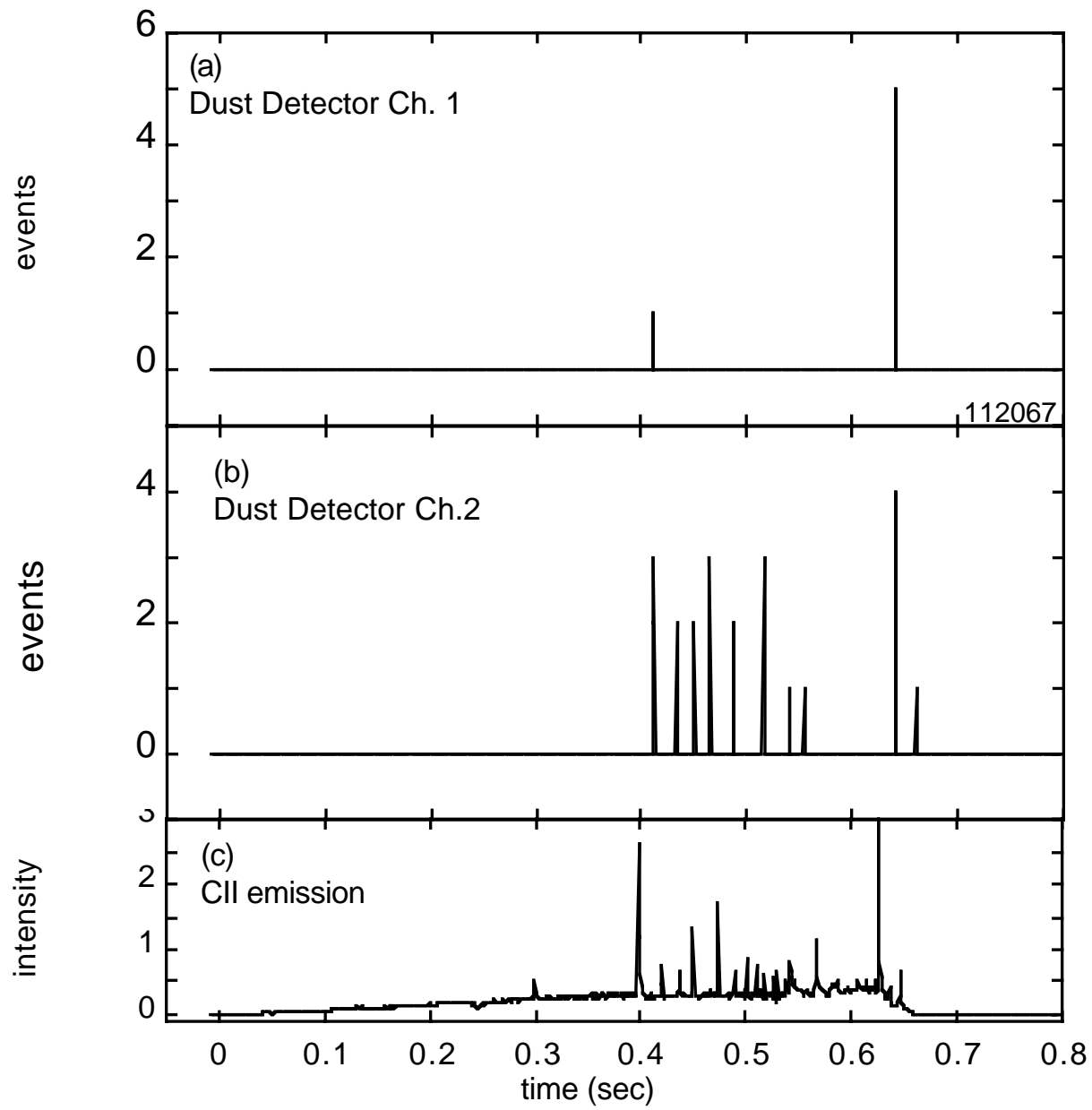

Fig. 10. First time resolved events recorded by the NSTX dust detector. Panel (a) shows the response of grid 1 and (b) of grid 2. The lower frame shows large transients in ionized carbon emission at 658 n.m.

Paper G13 C. H. Skinner et al. 


\section{External Distribution}

Plasma Research Laboratory, Australian National University, Australia

Professor I.R. Jones, Flinders University, Australia

Professor João Canalle, Instituto de Fisica DEQ/IF - UERJ, Brazil

Mr. Gerson O. Ludwig, Instituto Nacional de Pesquisas, Brazil

Dr. P.H. Sakanaka, Instituto Fisica, Brazil

The Librarian, Culham Laboratory, England

Mrs. S.A. Hutchinson, JET Library, England

Professor M.N. Bussac, Ecole Polytechnique, France

Librarian, Max-Planck-Institut für Plasmaphysik, Germany

Jolan Moldvai, Reports Library, Hungarian Academy of Sciences, Central Research Institute for Physics, Hungary

Dr. P. Kaw, Institute for Plasma Research, India

Ms. P.J. Pathak, Librarian, Institute for Plasma Research, India

Ms. Clelia De Palo, Associazione EURATOM-ENEA, Italy

Dr. G. Grosso, Instituto di Fisica del Plasma, Italy

Librarian, Naka Fusion Research Establishment, JAERI, Japan

Library, Laboratory for Complex Energy Processes, Institute for Advanced Study, Kyoto University, Japan

Research Information Center, National Institute for Fusion Science, Japan

Dr. O. Mitarai, Kyushu Tokai University, Japan

Dr. Jiangang Li, Institute of Plasma Physics, Chinese Academy of Sciences, People's Republic of China

Professor Yuping Huo, School of Physical Science and Technology, People's Republic of China

Library, Academia Sinica, Institute of Plasma Physics, People's Republic of China

Librarian, Institute of Physics, Chinese Academy of Sciences, People's Republic of China

Dr. S. Mirnov, TRINITI, Troitsk, Russian Federation, Russia

Dr. V.S. Strelkov, Kurchatov Institute, Russian Federation, Russia

Professor Peter Lukac, Katedra Fyziky Plazmy MFF UK, Mlynska dolina F-2, Komenskeho Univerzita, SK-842 15 Bratislava, Slovakia

Dr. G.S. Lee, Korea Basic Science Institute, South Korea

Institute for Plasma Research, University of Maryland, USA

Librarian, Fusion Energy Division, Oak Ridge National Laboratory, USA

Librarian, Institute of Fusion Studies, University of Texas, USA

Librarian, Magnetic Fusion Program, Lawrence Livermore National Laboratory, USA

Library, General Atomics, USA

Plasma Physics Group, Fusion Energy Research Program, University of California at San Diego, USA

Plasma Physics Library, Columbia University, USA

Alkesh Punjabi, Center for Fusion Research and Training, Hampton University, USA

Dr. W.M. Stacey, Fusion Research Center, Georgia Institute of Technology, USA

Dr. John Willis, U.S. Department of Energy, Office of Fusion Energy Sciences, USA

Mr. Paul H. Wright, Indianapolis, Indiana, USA 
The Princeton Plasma Physics Laboratory is operated by Princeton University under contract with the U.S. Department of Energy.

\author{
Information Services \\ Princeton Plasma Physics Laboratory \\ P.O. Box 451 \\ Princeton, NJ 08543
}

Phone: 609-243-2750

Fax: 609-243-2751

e-mail: pppl_info@pppl.gov

Internet Address: http://www.pppl.gov 